\title{
A NEW HIGH SPEED MEASURING MACHINE FOR
}

\section{ASTROMETRIC PLATES}

\author{
P. M. ROUTLY \\ U.S. Naval Observatory, Washington, D.C., U.S.A.
}

\begin{abstract}
A new 'Starscan' measuring machine has been built by Optronics International, Chelmsford, Mass., to specifications drawn up by the U.S. Naval Observatory. The accuracy and speed of operation of Starscan have been optimized for the measurement of astrometric plates. The following features in the design and operation of Starscan are discussed: (a) the granite stages, (b) interferometric stage position encoders, (c) the star centroid and integrated opacity detector, (d) the image profile display system, and (e) the function of the computer in machine control and data manipulation. The performance of Starscan, in terms of operating speed and accuracy, is reported for astrometric plates.
\end{abstract}

